\title{
ANÁLISE DA EXPANSÃO URBANA POR MEIO DE COMPOSIÇÕES COLORIDAS MULTITEMPORAIS
}

\author{
analysis of urban sprawl using multi-temporal colour composites \\ Rúbia Gomes Morato* \\ Fernando Shinji Kawakubo** \\ Ericson Hideki Hayakawa*** \\ Reinaldo Paul Pérez Machado****
}

\begin{abstract}
Resumo
Analisou-se a expansão urbana da região central do município de Embu, localizado à sudoeste da Região Metropolitana de São Paulo, num período de 32 anos, por meio de composições coloridas multitemporais. Para tal, fotografias aéreas de 1962, 1973 e 1994 foram geometricamente corrigidas usando um conjunto de cartas topográficas na escala 1:10 000. Em seguida, composições coloridas (RGB) multitemporais foram construídas. Os resultados mostram, em cores distintas, o arruamento e as edificações, de acordo com o período em que foram instalados. As áreas em que não ocorreram mudanças em tons de cinza. Para facilitar a análise do crescimento urbano, foi feita uma classificação utilizando as fotografias aéreas multitemporais. Esta classificação possibilitou a geração da carta de transformações no uso da terra contendo oito classes de mudanças.
\end{abstract}

Palavras-chave: Expansão urbana, fotografias aéreas, composições coloridas multitemporais.

\begin{abstract}
The urban growth at central area of Embu municipality, south-western metropolitan region of the state of São Paulo was assessed. The urban sprawl was analysed over a period of 32 years by means of multitempora colour composites. Aerial photography taken in 1962, 1963 and 1994 were, initially, geometrically corrected using a set of topographic charts (1: 10000 scale). Subsequently, RGB colour composites were build up using the aerial photography. Through this approach, changes over the years were exhibited in colours and no-changes in grey-tones. To facilitate the analysis, a supervised classification scheme was performed. The final classification included eight types of land-use land-cover changes.
\end{abstract}

Key words: Urban sprawl, aerial photography, multitemporal colour composites.

\section{Resumen}

Se analizó la expansión urbana de la región central del municipio de Embu, localizado al sudoeste de la Región Metropolitana de São Paulo, en un período de 32 años, por medio de composiciones coloridas multitemporales. Para tal, fotografías aéreas de 1962, 1973 e 1994 fueron geométricamente corregidas usando un conjunto de cartas topográficas en escala 1:10.000. En seguida, se construyeron composiciones coloridas (RGB) multitemporales. Los resultados muestran en colores diferentes las vías y las edificaciones, de acuerdo con el período en que fueron instalados. Las áreas en que no ocurrieron cambios aparecen en tonalidades de gris. Para facilitar el análisis del crecimiento urbano, se realizó una clasificación utilizando fotografías aéreas multitemporales. Esta clasificación posibilitó la generación de la carta de transformaciones en el uso de la tierra conteniendo ocho clases distintas de cambios.

Palabras clave: Expansión urbana, fotografías aéreas, composiciones coloridas multitemporales.

(*) Prof ${ }^{\mathrm{a}}$. Dr ${ }^{\mathrm{a}}$. do Instituto de Ciências da Natureza, Universidade Federal de Alfenas - Rua Gabriel Monteiro da Silva, 700, Centro, CEP: 37.130-000, Alfenas, (MG) - Brasil, Tel: (+ 55 35) 32991449 - rubiagm@usp.br

(**) Prof. Dr. do Instituto de Ciências da Natureza, Universidade Federal de Alfenas - Rua Gabriel Monteiro da Silva, 700, Centro, CEP: 37.130-000, Alfenas, (MG) - Brasil, Tel: (+ 55 35) 32991449 - fskgeo@gmail.com

(***) Prof ${ }^{a}$. Msc. do Instituto de Ciências da Natureza, Universidade Federal de Alfenas - Rua Gabriel Monteiro da Silva, 700 , Centro, CEP: 37.130-000, Alfenas ,(MG) - Brasil, Tel: (+55 35) 32991449 - ericson_geo@yahoo.com.br

(****) Prof. Dr. do Departamento de Geografia da Universidade de São Paulo - Av Prof. Lineu Prestes, 138, Butantã, CEP: 05508-000, São Paulo (SP) - Brasil, Tel/Fax: (+55 11) 30913769 / 30913159 - rpmgis@usp.br 


\section{INTRODUÇÃO}

O crescimento urbano tem ocorrido de modo acelerado e desordenado na maioria das cidades brasileiras. A falta de informações precisas e atualizadas a respeito do crescimento urbano tem trazido grandes dificuldades aos órgãos públicos para definir uma política eficaz de acompanhamento e controle desta expansão desordenada.

Atualmente, um dos principais recursos utilizados para a análise e monitoramento do crescimento urbano consiste na utilização da tecnologia do Sensoriamento Remoto em conjunto com os Sistemas de Informações Geográficas (SIGs).

Tradicionalmente, o Sensoriamento Remoto aplicado à análise urbana faz uso de fotografias aéreas obtidas por meio de técnicas de fotogrametria (BOWDEN, 1975). As fotografias aéreas além de fornecer alta resolução espacial (com detalhes de alguns centímetros no terreno, dependendo da escala da foto), constituem instrumentos valiosos que possibilitam reconstituir o processo de ocupação do ambiente urbano em séries temporais médias e longas. A grande dificuldade encontrada na utilização de fotografias aéreas para o monitoramento do crescimento urbano consiste nos altos custos que envolvem as execuções periódicas de levantamentos aerofotogramétricos (FORESTI; HAMBURGER, 1995).

Até recentemente, as imagens obtidas por meio de plataformas orbitais eram pouco eficientes para aplicações relacionadas ao ambiente urbano. Esta limitação se configurava principalmente por causa da baixa resolução espacial fornecida pelos principais sistemas em operação, como por exemplo, do Landsat Multispectral Scanner System (MSS) e Thematic Mapper (TM) - com resoluções de 79 e 30 metros no terreno, respectivamente. Além da necessidade de aquisição de imagens com resolução mais fina para este tipo de ambiente (especialmente para aplicações intra-urbanas), a extração de informações também era comprometida em função das diversidades dos padrões de uso/ocupação do solo e da alta variabilidade dos materiais envolvidos.

Com os avanços da tecnologia aeroespacial, as resoluções espaciais dos sistemas-sensores têm aumentado continuamente. O ano de 1999 foi um marco para o sensoriamento remoto. Naquele ano, foi lançado o satélite IKONOS II equipado com sensor que gera imagens de 1 metro de resolução no terreno no modo pancromático e 4 metros no multiespectral. O IKONOS II foi o primeiro satélite comercial de alta resolução lançado até então. Inúmeros outros sistemas sensores equipados com câmeras de alta resolução têm sido lançados ao longo dos anos, como por exemplo, o Quick Bird (61-72 centímetros no modo pancromático e 2,4-2,8 metros no multiespectral), Rapid Eye (6,5 metros no modo multiespectral) e o satélite Cino-Brasileiro CBERS-2B que carrega o sensor High Resolution Camera (2,7 metros no pancromático). O lançamento destes novos satélites tem ampliado notavelmente o potencial do sensoriamento remoto para as aplicações urbanas.

Além destes novos satélites, os procedimentos de interpretação de imagens que se baseiam em abordagens cognitivas, como é o caso do software eCognition tem trazido grandes contribuições no sensoriamento remoto de alta resolução espacial.

A análise das transformações no uso da terra/cobertura vegetal utilizando sensoriamento remoto fundamenta-se na suposição de que as mudanças observadas nas respostas espectrais do pixel registradas em duas ou mais datas correspondem, além das mudanças no ambiente, também aos efeitos atmosféricos e de degradação do sensor (JENSEN, 2005). As mudanças no ambiente são passíveis de serem quantificadas utilizando vários métodos de processamento digital de imagens. Antes de realizar a análise de mudança, é importante que as imagens sejam submetidas a um procedimento de calibração radiométrica, como forma de compensar as diferenças atmosféricas, de iluminação e de desempenho do sensor. 
No geral, as abordagens empregadas para avaliar as mudanças ao longo do tempo são agrupadas em dois modos: métodos de realce e métodos comparativos pós-classificação. No primeiro caso, novas imagens são geradas como forma de realçar as mudanças registradas ao longo do tempo, enquanto no segundo, as mudanças são analisadas comparando individualmente os resultados das classificações (SINGH, 1989).

O trabalho aqui apresentado utiliza uma abordagem híbrida que combina o método de realce por meio de Composições Coloridas Multi-temporais (CCMT) seguido pela classificação das mudanças utilizando um classificador supervisionado. As CCMT foram geradas fazendo-se uso de três imagens de datas diferentes, que foram associadas aos filtros de cores RGB (Red, Green e Blue). As mudanças produzidas ao longo do tempo foram destacadas em cores e as áreas que não tiveram mudanças em tonalidades de cinza, que variam do preto ao branco. Ou seja, os resultados produziram imagens coloridas artificialmente ressaltando as mudanças observadas. Finalmente, se criou uma carta com a representação temática diacrônica dos câmbios produzidos no território analisado.

Por causa da simplicidade da técnica e rapidez com que as mudanças são evidenciadas, as CCMT têm sido utilizadas em diversas aplicações, como por exemplo: nas mudanças do estado fenológico da vegetação (EYTON, 1983); nos estudos de variação da lâmina d'água em áreas de várzea (PINTO et al. 1985; FLORENZANO et al. 1988); na análise de processos de erosivos e deposicionais ao longo da linha de costa (KAWAKUBO; LUCHIARI, 2002), em estudos de desmatamento (ADAMS et al. 1995; SHIMABUKURO et al. 1999), na detecção de danos produzidos por queimadas e posterior recuperação da vegetação (RICHARDS, 1984) e também para avaliar a dinâmica da expansão urbana (PEREIRA et al. 1984; FORESTI et al. 1986) etc.

\section{ÁREA DE ESTUDO}

A área selecionada está localizada na região central do município de Embu (abrangendo aproximadamente uma área de 4,4 km2 de extensão) sudoeste da Região Metropolitana de São Paulo (RMSP).

O município de Embu é muito representativo em relação ao processo de expansão urbana ocorrido na RMSP nas últimas décadas. As taxas de crescimento relativo da população da RMSP nesse período são muito altas; no município de Embu essas taxas são ainda maiores. Entretanto, é importante ressaltar que como essas taxas são relativas, municípios que no início do período analisado possuíam maior população, tendem a apresentar menores taxas de crescimentos relativos, mesmo que o incremento populacional seja maior em termos absolutos (MORATO, 2009). A Tabela 1 mostra o crescimento da população de Embu.

Quadro 1 - Pessoas Residentes no Município de Embu e na RMSP entre 1960 e 2000.

\begin{tabular}{|c|c|c|c|c|}
\hline ANO & $\begin{array}{c}\text { POPULAÇÃO DE EMBU } \\
\text { (ABSOLUTO) }\end{array}$ & $\begin{array}{c}\text { CRESCIMENTO MÉDIO } \\
\text { ANUAL DE EMBU (\%) }\end{array}$ & $\begin{array}{c}\text { POPULAÇÃO DA RMSP } \\
\text { (ABSOLUTO) }\end{array}$ & $\begin{array}{c}\text { CRESCIMENTO MÉDIO } \\
\text { ANUAL DA RMSP (\%) }\end{array}$ \\
\hline 1960 & 5.041 & - & 4739409 & 17,17 \\
\hline 1970 & 18.161 & 36,02 & 8139730 & 15,46 \\
\hline 1980 & 65.075 & 35,83 & 12588725 & 11,15 \\
\hline 1991 & 154.739 & 21,61 & 15444941 & 12,86 \\
\hline 2000 & 206.781 & 14,84 & 17878703 & \\
\hline
\end{tabular}

Fonte: Instituto Brasileiro de Geografia e Estatística.

O crescimento da mancha urbana de Embu se deu em dois eixos principais: o da Rodovia BR 116 e o da Estrada de Itapecerica. Este padrão é classificado por Foresti (1986) como tentacular, 
formando uma malha urbanizada contínua que parte da região central da cidade de São Paulo e se prolonga em direção às principais rodovias.

A rodovia BR-116 foi decisiva para o crescimento populacional do município. Aberta em 1961, incentivou a instalação de indústrias, que atraiu a população de trabalhadores. Paralelamente, a participação de Embu como cidade-dormitório de São Paulo e o desenvolvimento da atividade turística também contribuíram para esse crescimento.

\section{MATERIAIS E MÉTODO}

Foram utilizadas fotografias aéreas de 1962, 1973 e 1994. As fotografias aéreas foram, inicialmente, digitalizadas por meio de um scanner de mesa. A resolução definida para a digitalização das fotografias foi de 500 DPIs. Foram utilizadas no total oito fotografias aéreas na escala 1: 25000 cedidas pelo Arquivo de Fotografias Aéreas (AFA) do Departamento de Geografia da USP: quatro fotografias do voo de 1962, realizado pela Secretaria da Agricultura do Estado de São Paulo; duas do voo 1973 e; outras duas do voo de 1994 realizados pela BASE S/A.

Após a digitalização, as fotografias aéreas foram importadas para o Sistema de Informação Geográfica (SIG) ILWIS 3.6. O ILWIS é um software livre e de código aberto desenvolvido pelo ITC (Faculty of Geo-Information Science and Earth Observation), University of Twente, da Holanda. Este sistema contém uma ampla gama de recursos voltados para entrada de dados (digitalização e vetorização em tela), edição, recuperação, análise espacial e processamento de imagens de sensoriamento remoto (KOOLHOVEN et al. 2007). O programa pode ser obtido, gratuitamente, na página eletrônica http://52north.org.

Inicialmente, as fotografias aéreas foram calibradas radiometricamente, como forma de reduzir as variações de brilho entre as imagens. A metodologia empregada, denominada de retificação radiométrica (HALL et al. 1991), seleciona a média dos alvos claros e escuros nas imagens que não mudaram ao longo do tempo. Em seguida, uma transformação linear é aplicada:

$$
\mathrm{T}=\mathrm{m} * \mathrm{x}+\mathrm{b}
$$

onde:

$\mathrm{T}=$ valor da imagem retificada;

$\mathrm{x}=$ valor da imagem original;

$\mathrm{m}=(\mathrm{Br}-\mathrm{Dr}) /(\mathrm{Bs}-\mathrm{Ds})$;

$\mathrm{b}=(\mathrm{Dr} * \mathrm{Bs}-\mathrm{Ds} * \mathrm{Br}) /(\mathrm{Bs}-\mathrm{Ds})$

e onde:

$\mathrm{Br}=$ média do conjunto de referência clara;

$\mathrm{Dr}=$ média do conjunto de referência escura;

Bs = média do conjunto claro a ser retificado;

Ds $=$ média do conjunto escuro a ser retificado.

Adotou-se como referência para a retificação radiométrica os valores médios dos pixels claros e escuros extraídos das fotografias aéreas de 1994.

A correção geométrica e o mosaico das fotografias aéreas foram feitos por meio de pontos de controle identificados nas imagens na base cartográfica de escala 1: 10.000 da EMPLASA (1981). Foram selecionados no processo de georeferenciamento mais de 50 pontos de controle para cada ano. As fotografias aéreas foram reamostradas com o algoritmo interpolador denominado de convolução cúbica, que é método de interpolação mais adequado para este tipo de produto (JENSEN, 
2005). O registro dos mosaicos das fotografias aéreas é fundamental para que as feições observadas nas fotografias aéreas coincidam perfeitamente no terreno.

Nas composições coloridas multi-temporais (CCMT) geradas neste estudo, as áreas em que não ocorreram mudanças aparecem em tonalidades de cinza (feições altamente correlacionadas e que se posicionam ao longo do eixo acromático) e as áreas com mudanças, em cores - em razão das diferenças de refletâncias observadas.

Com o objetivo de facilitar a interpretação, a CCMT final foi submetida à classificação, que permitiu a geração de uma Carta de Transformações do Uso da Terra/Cobertura Vegetal. Para tal, diferentes amostras de treinamento foram selecionadas e adicionadas ao sistema classificador, do tipo supervisionado (onde o operador decide o nome e o número de categorias de uso que serão produzidas). Tomou-se o cuidado de selecionar várias amostras representativas de cada classe. Em seguida, o classificador por Máxima Verossimilhança (Maxver) foi utilizado para associar cada pixel da imagem a uma determinada classe definida no mapeamento.

$\mathrm{Na}$ fase de elaboração do mapeamento, e para ajudar a complementar as imagens utilizadas na confecção das CCMT, foram feitas visitas ao terreno, realizando procedimentos habituais de reambulação, como são conhecidos na especialidade de aerofotogrametria. Tais procedimentos, unidos aos dados aportados pela base cartográfica utilizada (EMPLASA,1981), permitiram a inclusão, verificação e atualização de valiosas informações, atributos temáticos e topônimos, que são de fundamental importância na confecção do mapeamento.

\section{RESULTADOS E DISCUSSÕES}

Notadamente a partir da década de 1960 o município de Embu passou por grandes transformações - marcado por um acelerado crescimento da mancha urbana. A figura 1 ilustra este crescimento para o período de 32 anos a partir das fotografias aéreas verticais tomadas em 1962, 1973 e 1994.

As manchas em branco (feições de alta refletância) correspondem a áreas de solo exposto e terrenos construídos. As manchas com tonalidade de cinza média (feições de média refletância) correspondem às áreas de pastagens e terrenos baldios. Por fim, as manchas escuras (feições de baixa refletância) referem-se às áreas de mata e corpos de água.

Observa-se um notável crescimento urbano ao longo da rodovia. A construção da BR-116 fez com que inúmeras indústrias fossem instaladas na região. Oliveira (1972) afirma que das 25 indústrias existentes no início da década de 1970, apenas duas tiveram instalação anterior a 1960, o que mostra sua importância para a economia do município.

Foram realizados vários testes de CCMT como forma de realçar as mudanças observadas ao longo das datas analisadas. O arranjo que forneceu o melhor resultado foi: filtro vermelho (Red) associado à fotografia área de 1964; o verde (Green) à de 1973; e o azul (Blue) à de 1994. A Figura 2 ilustra de modo simplificado o processo de formação das cores utilizando este arranjo. 


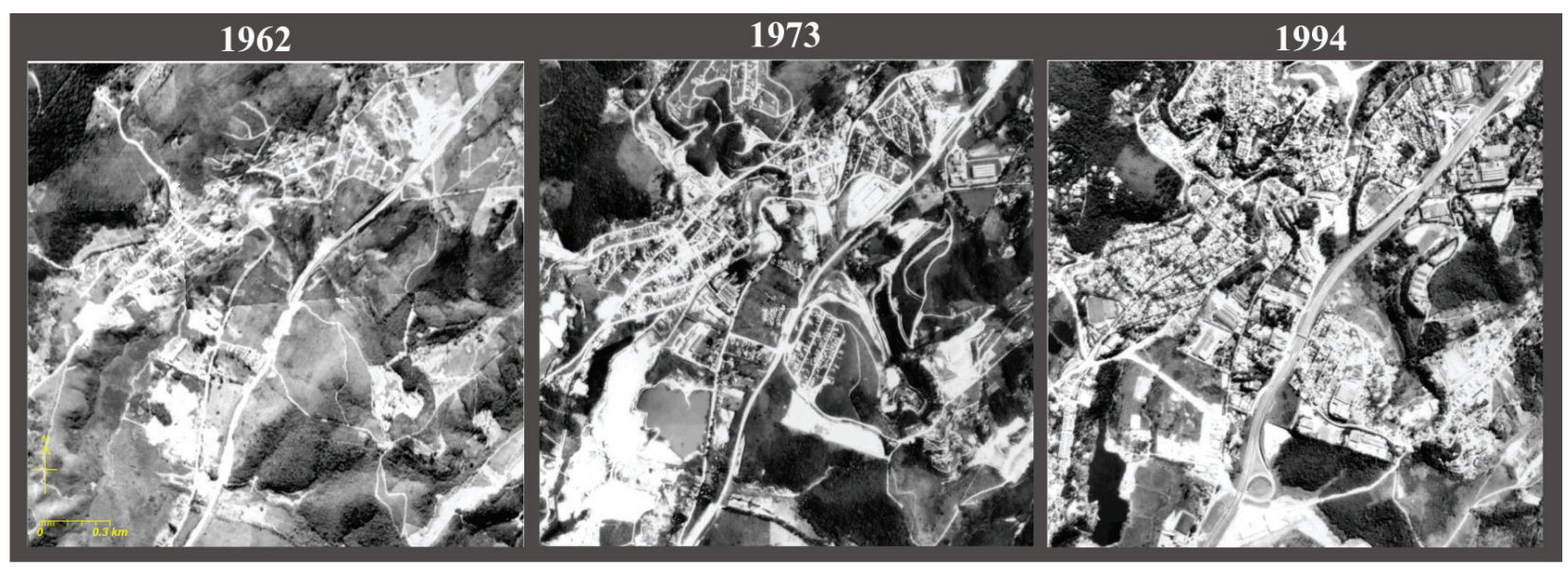

Figura 1 - Mosaicos das fotografias aéreas de 1962, 1973 e 1994, respectivamente. As fotografias foram retificadas radiometricamente utilizando a metodologia de Hall (1991). O mosaico de 1994 foi adotando como referencia para a retificação.

Vermelho (1972)
Verde (1973)
Azul (1994)
Cor Resultante

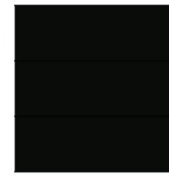

Preto
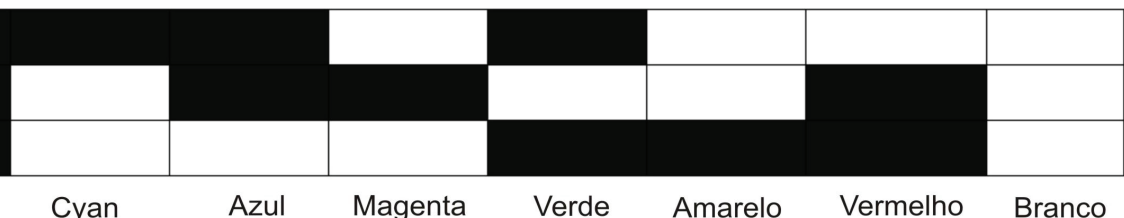

Período de Alta Reflectância

Período de Baixa Reflectância

Figura 2 - Modelo simplificado da formação das cores na composição colorida multitemporal - CCMT (Adaptado de EYTON, 1983). Quando não ocorrem mudanças, as feições aparecem em tonalidades de cinza que variam do preto (baixa ou nula de refletância) ao branco (alta ou máxima refletância). As cores aparecem em função das diferenças de refletância em uma ou outra data.

A figura 3 ilustra o resultado da CCMT utilizando o arranjo 1962 (R), 1973(G) e 1994(B). As áreas em que não ocorreram mudanças aparecem em tonalidades que variam do preto ao branco (eixo acromático). As mudanças são realçadas por meio de cores.

$\mathrm{Na}$ CCMT as áreas correspondentes ao sistema viário e às edificações existentes desde 1962 apresentam-se em branco, pois possuem alta refletância nas três datas. É assim que se observa predominantemente a BR-116, os arruamentos da região central e as respectivas edificações. Remanescentes de matas também são observados a noroeste, leste e sudeste (em cinza escuro e preto). Estas áreas não foram incorporadas pelo processo de expansão urbana devido às altas declividades do terreno, que dificultaram sua ocupação, talvez em combinação com a aplicação de medidas de preservação ambiental mais rigorosas.

Observa-se que em 1973 novos loteamentos são abertos nas regiões do Jardim Sadie e Jardim Sílvia (alinhamentos com a cor verde). Estes loteamentos ocupam áreas de terrenos com altas declividades. A ocupação ainda é rarefeita e se intensifica com o passar dos anos (em ciano). Indústrias como a Sansuy, a Herta, a Mallory, a Vitro Sul estão instaladas.

Destaca-se o caso do Jardim Sílvia, onde residem famílias de baixa renda em autoconstruções. Segundo Garibaldi (1998), neste bairro existe a ocorrência de escorregamentos, em geral ligados às intervenções realizadas pelos moradores sem critério técnico, vazamentos na rede de abastecimento d'água e principalmente lançamento de água servida em superfície. 


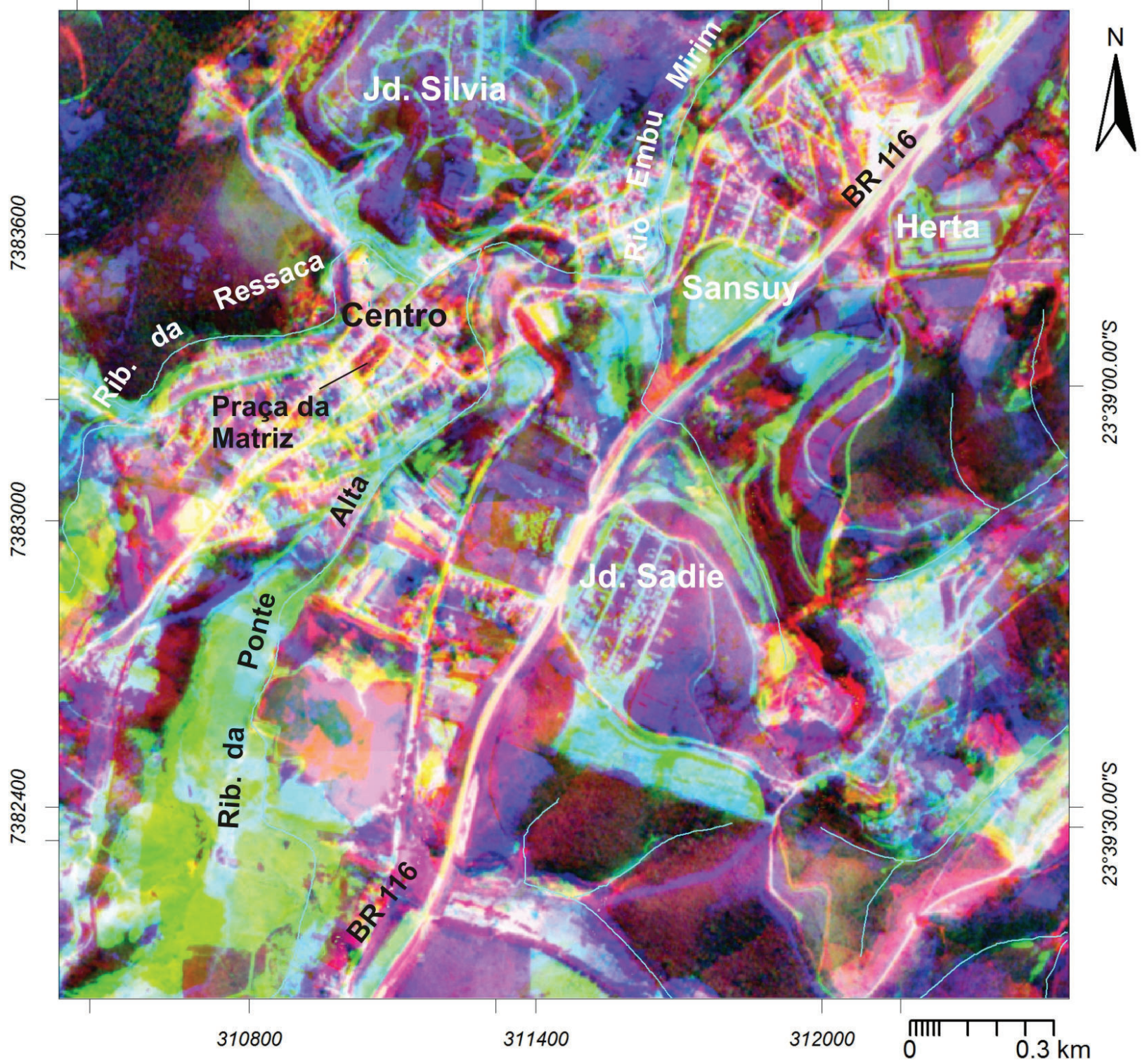

Figura 3 - Composição colorida multitemporal 1962(R), 1973(G) e 1994(B). As áreas que não mudaram são reapresentadas com tonalidades que variam do preto - baixa refletância $(\downarrow)$ ao branco - alta refletância $(\uparrow)$. As cores representam as mudanças: vermelho $=\uparrow$ refletância em 1962; verde $=\uparrow$ refletância em 1973; azul $=\uparrow$ refletância em 1994; amarelo $=\uparrow$ refletância em 1962 e 1973; magenta $=\uparrow$ refletância em 1962 e 1994; ciano $=\uparrow$ refletância em 1973 e 1994. 
A mancha verde ao longo do Ribeirão das Pontes Altas (eixo sudoeste da imagem) refere-se à presença em 1973 de uma área de mineração. Esta área de mineração foi desativada em $1994 \mathrm{e}$ recuperada para dar lugar a um parque, compensação ambiental do Programa de Recuperação e Saneamento da Bacia do Guarapiranga. A cor ciano nas proximidades deste parque corresponde a instalações industriais e residenciais que também ocuparam a área deste antigo porto.

$\mathrm{Na}$ fotografia aérea de 1994 inúmeras mudanças são observadas. Além do aumento da densidade de ocupação na região central, no Jardim Sadie, no Jardim Sílvia e no Jardim Magali, a BR-116 encontra-se duplicada. Outras indústrias são instaladas, como a Italforja e a Esco. O Estádio Municipal está construído. Todas estas feições apresentam-se na composição destacadas na cor magenta. Ou seja, construções que ocuparam áreas com alta refletância em 1962, como por exemplo, terrenos baldios com presença de solo exposto.

$\mathrm{Na}$ região do centro, em 1994, algumas ruas apresentam-se com maior arborização que em 1962 e 1973. Estas ruas são realçadas na CCMT em amarelo.

Analisando mais detalhadamente a CCMT, é possível acompanhar o crescimento das copas das árvores ao longo dos anos. Na Praça da Matriz (localizada no centro), em 1962, as copas das árvores ainda não se encontravam desenvolvidas. Como conseqüência, a radiação eletromagnética sofria forte influência do efeito do solo (background). Em 1973 observa-se uma diminuição da reflexão da radiação devido ao incremento do dossel, porém ainda é possível visualizar individualmente os pés das árvores. A diminuição da refletância contrasta-se com a alta refletância da rua que a circunda. Em 1994, as copas das árvores encontram-se bem estruturadas e extravasam os limites da praça, cobrindo também a rua. Como resultado, na CCMT, os limites interiores da praça estão em vermelho e seu contorno externo (delimitado pela rua) em amarelo.

Como forma de simplificar a codificação da CCMT, uma classificação supervisionada foi realizada. Esta classificação possibilitou a geração da Carta de Transformação do Uso da Terra/ Cobertura Vegetal entre 1962, 1973 e 1994 (Figura 4). Oito classes que contêm informações do tipo de uso/cobertura vegetal e das transformações ocorridas ao longo dos anos foram definidas na classificação: as três primeiras classes (1, 2 e 3$)$ correspondem às mudanças em áreas construídas; as classes restantes $(4,5,6,7$ e 8$)$ referem-se às mudanças relacionadas à cobertura vegetal. 


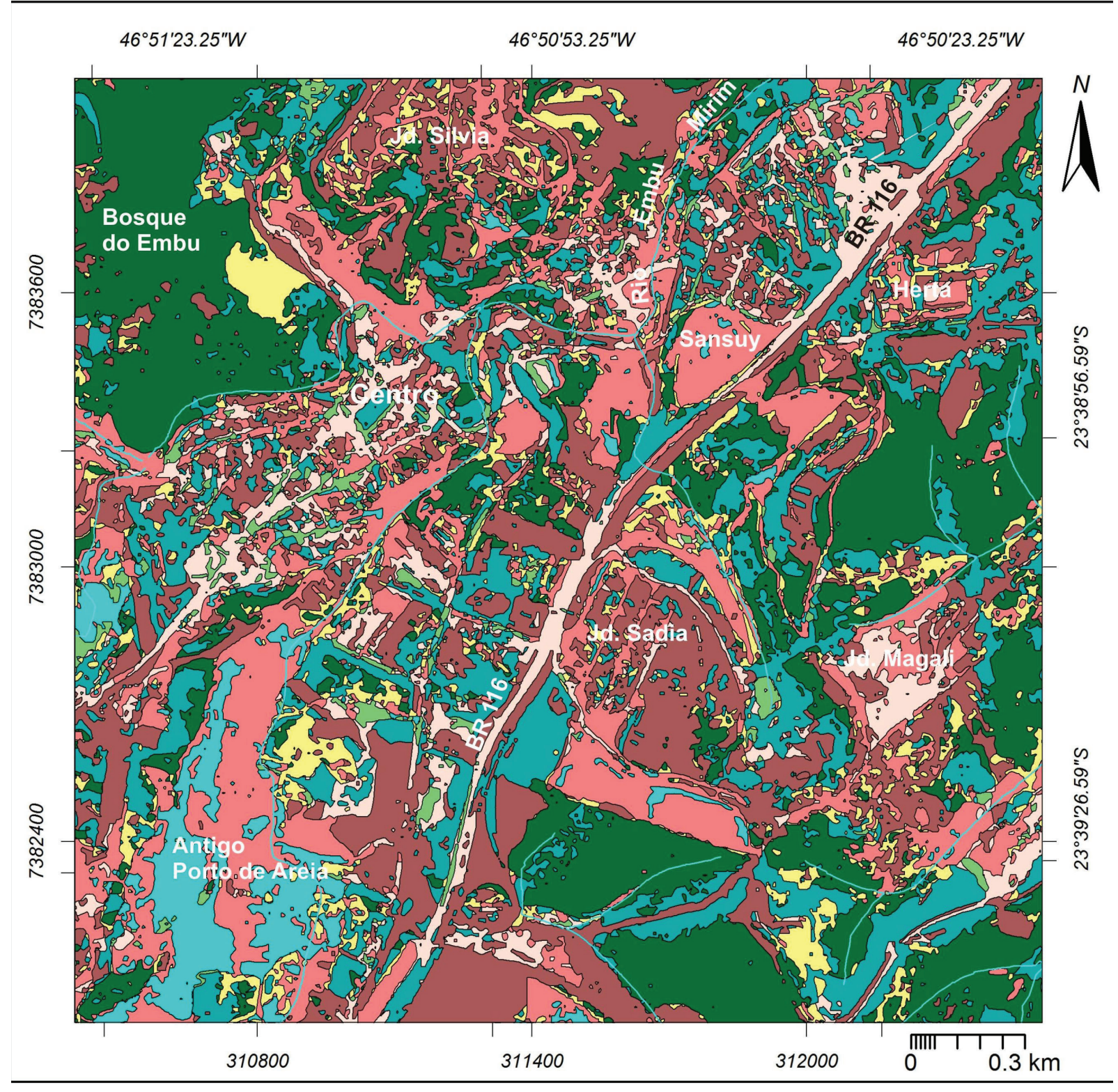

1: Sistema Viário e Edificações anteriores a 1962

2: Sistema Viário e Áreas Edificadas em 1973

3: Sistema Viário e Áreas Edificadas em 1994

4: Ảreas com Vegetação em 1962, Desmatadas em 1973 e em Recomposição e/ou Arborizadas em 1994

5: Areas sem Vegetação em 1962 e 1973 e em Recomposição e/ou Arborizadas em 1994

6: Áreas sem Vegetação em 1962 e Arborizadas em 1973 e 1994

7: Áreas com Vegetação Densa entre 1962 e 1994

8: Áreas com Campo entre 1962 e 1994

Figura 4 - Carta de Transformações do Uso da Terra/Cobertura Vegetal utilizando fotografias aéreas de 1962 , 1973 e 1994. 


\section{CONSIDERAÇÕES FINAIS}

A técnica de composição colorida multitemporal (CCMT) mostrou-se eficiente para a análise da expansão urbana utilizando fotografias aéreas convencionais não coloridas. A metodologia aqui empregada permitiu que os fotogramas fossem submetidos ao tratamento digital de imagens e a métodos de classificação que, costumeiramente, são aplicados a imagens digitais satelitárias. As mudanças foram realçadas em cores e as áreas onde não ocorreram alterações em tonalidades de cinza. As alterações mais evidentes ocorreram nas áreas periféricas que foram desmatadas para serem urbanizadas. Mudanças intra-urbanas também foram evidenciadas na CCMT, com o aumento da arborização/ajardinamento e edificações de terrenos vazios.

- A técnica da CCMT é simples, porém, exige do usuário um bom conhecimento da teoria das cores (aditivas e subtrativas) para a interpretação das mudanças.

- A posterior classificação supervisionada facilitou a criação da carta de Transformações do Uso da Terra/Cobertura Vegetal final.

- A calibração radiométrica das imagens se revelou como outro ponto importante que deve ser considerado principalmente quando as fotografias aéreas possuem grandes diferenças de brilho entre as datas.

- Em relação ao registro (correção geométrica), todas as fotografias devem coincidir perfeitamente no terreno, para que não haja problemas de deslocamento das feições, e também para permitir a sobreposição de elementos vetoriais.

A metodologia aqui apresentada é uma combinação de abordagens próprias de estudos de Sensoriamento Remoto; no entanto, deve-se ressaltar a importância dos procedimentos de reambulação, que são os que permitem a identificação correta de usos complexos e atributos das feições urbanas e seus topônimos, dentre outros. Tais atributos são, obviamente, invisíveis nas imagens, sejam elas orbitais ou fotográficas.

\section{AGRADECIMENTOS}

Ao Laboratório de Aerofotogeografia e Sensoriamento Remoto (LASERE) e ao Arquivo de Fotografias Aéreas (AFA) do Departamento de Geografia, Faculdade de Filosofia Letras e Ciências Humanas da Universidade de São Paulo - USP pelo fornecimento do material cartográfico utilizado neste trabalho.

\section{REFERÊNCIA BIBLIOGRÁFICA}

ADAMS, J. B.; SABOL, D. E.; KAPOS, V.; AILMEIDA FILHO, R.; ROBERTS, D. A.; SMITH, M. O.; GILLESPIE, A. R. Classification of multispectral images based on fractions of endmembers: application to land-cover change in the Brazilian Amazon. Remote Sensing of Environmentn New York, v. 52, p. 137-154, 1995.

BOWDEN, L. W. Urban environments: inventory and analysis. In: AMERICAN SOCIETY OF PHOTOGRAMMETRY. Manual of Remote Sensing. VA: Falls Church, 1975. p. 1815-1880.

EMPLASA Carta topográfica na escala 1:10 000 da folha Embu. São Paulo: EMPLASA, 1981.

EYTON, J. R. Landsat multitemporal color composites. Photogrammetric Engineering \& Remote Sensing. Maryland, p. 231-235, 1983. 
FLORENZANO, T. G.; PINTO, S. A. F.; FILHO, M. V.; NOVO, E. L. M.; KUX, H. J. H. Utilização de dados TM-LANDSAT para mapeamento de áreas submetidas a inundação na bacia do rio Parnaíba. Relatório Interno do INPE-4570-RPE/566. São José dos Campo, p. 1-50, 1988.

FORESTI, C. Avaliação e Monitoramento Ambiental da Expansão Urbana no Setor Oeste da Área Metropolitana de São Paulo: análise através de dados e técnicas de sensoriamento Remoto. 1986. Tese (Doutorado em Geografia) - Departamento de Geografia da Faculdade de Filosofia, Letras e Ciências Humanas da Universidade de São Paulo, São Paulo, 1986.

FORESTI, C.; HAMBURGER, S. S. Sensoriamento remoto aplicado ao estudo do uso do solo urbano. In: TAUK-TORNISIELD, S. M.; GOBBI, N.; FOWLER, H. G. Análise Ambiental: uma visão multidisciplinar. São Paulo: Editora Unesp, 1995, p.143-149.

GARIBALDI, C. M. Cartografia de Riscos Geológicos Associados a Escorregamentos no Município de Embu - RMSP. São Paulo, 1998. 155f. Dissertação (Mestrado em Engenharia) - Departamento de Engenharia Civil da Escola Politécnica da Universidade de São Paulo, São Paulo, 1998.

HALL, F.G.; STREBEL, D.E.; NICKESON, J.E.; GOETZ, S.J. Radiometric rectification: toward a common radiometric response among multidate, multisensor images. Remote Sensing of Environment. New York, v.35, p.11-27, 1991.

JENSEN, J. R. Introductory digital image processing: a remote sensing perspective. USA: Prentice Hall, 2005. KAWAKUBO, F. S.; LUCHIARI, A. Estudo da morfodinâmica da Barra do Icapara - SP com apoio de imagens obtidas por meio de sensoriamente remoto orbital. Brazilian Journal of Oceanography. São Paulo, n. 50, P. 59-62, 2002.

KOOLHOVEN, W.; HENDRIKSE, J.; NIEUWENHUIS, W; RETSIOS, B.; SCHOUWENBURG, M.; WANG, L.; BUDDE, P.; RAYMOND, N. ILWIS Open. Holanda: ITC, 2007.

MORATO, R. G. Geografia do bem estar: análise especial de um índice de qualidade de vida urbana. In: Prêmio Ence 50 Anos: o Censo 2000 e a Pesquisa Social no Brasil. Rio de Janeiro: IBGE, 2009. p.133-160. OLIVEIRA, M. N. L. Embu e sua Participação no Conjunto da Faixa Periférica da Metrópole Paulistana. 1972. Dissertação (Mestrado em Geografia) - Departamento de Geografia da Faculdade de Filosofia, Letras e Ciências Humanas da Universidade de São Paulo, São Paulo, 1972.

PEREIRA, M. N.; KURKDJIAN, M. L. N. O.; FORESTI, C.; UBIRAJARA, M. B. 1984. Aplicações de composições coloridas multitemporais obtidas a partir de dados Landsat no estudo de crescimento urbano. In: SIMPÓSIO BRASILEIRO DE SENSORIAMENTO REMOTO, 1984, Rio de Janeiro. Anais... São José dos Campos: INPE, 1984.

PINTO, S, A, F.; NOVO, E. M. L. M.; NIERO, M.; ROSA, R. 1985. Utilização de dados multitemporais do Landsat para a identificação de setores da planície fluvial sujeitos à inundação. Relatório Interno do INPE-3445-PRE/699. São José dos Campos, p.1-25, 1985.

RICHARDS, J. A.; Thematic mapping from multitemporal image data using the principal component transformation. Remote Sensing of Environment. New York, v. 16, p. 35-46, 1984.

SHIMABUKURO, Y. E. ; DUARTE, V. ; MELLO, E. M. K. ; MOREIRA, J. C. RGB shade fraction images derived from multitemporal Landsat TM data for studying deforestation in the Brazilian Amazon. International Journal of Remote Sensing. London, v. 20, n. 4, p. 643-646, 1999.

SINGH, A. 1989 Digital change detection techniques using remotely-sensed data. International Journal of Remote Sensing. London, v.10, n.6, p.989-1003, 1989.

WESTEN, C.; FARIFTEH, J. ILWIS - integrated land and water information system: user's guide. Enschede: International Institute for Aerospace Survey \& Earth Sciences, 1997.

Trabalho enviado em julho de 2011 Trabalho aceito em agosto de 2011 